\title{
Comparative Evaluation of Sri Lanka Tall and Dwarf $x$ Tall Coconut Hybrids for Tolerance to Weligama Coconut Leaf Wilt Disease in Sri Lanka
}

\author{
S.A.C.N. Perera*, K.P. Waidyarathne, H.D.M.A.C. Dissanayaka, N.P.A.D. Nainanayake and \\ G.K. Ekanayake
}

\begin{abstract}
Weligama Coconut Leaf Wilt Disease (WCLWD) is a phytoplasma disease found in Southern Sri Lanka. It is an incurable, debilitating disease resulting in yield loss and ultimate death of the palm and over 250,000 palms have been identified to be infected. Breeding coconuts for resistance is a viable option in managing incurable diseases and for this WCLWD resistant germplasm is needed. Accordingly, the objective of the current research was to investigate the comparable levels of WCLWD resistance of Sri Lanka tall and CRIC65 coconut cultivars which are favoured in Sri Lanka.

Eight coconut estates which were planted with Sri Lanka tall (SLT) and CRIC65 hybrids as a mixed plantation or in close proximity were observed. Out of them an extent of about 04 acres of one estate was selected for detailed analysis using the disease severity index developed based on the WCLWD symptoms; flaccidity, leaf yellowing and marginal necrosis of leaflets.

General observations indicated the presence of WCLWD in both SLT and the hybrid CRIC65. Marginal necrosis was at a minimal level in both the cultivars, while the other symptoms; flaccidity and yellowing scored higher values at all levels in the spiral in SLT than in hybrid CRIC65. Moreover, the hybrid coconut CRIC65 displayed lower percentage of disease incidence and significant reduction in the levels of the main symptom flaccidity. As a result, the hybrid palms recorded significantly low disease index value than SLT. Moreover, disease incidence was observed to be low in properly managed estates irrespective of the cultivar. With the findings of the current study, coconut varieties SLGD and selected SLT which remain healthy under the same disease pressure can be recommended as parents in a breeding programme aiming at resistance/tolerance to WCLWD.
\end{abstract}

Keywords: Coconut hybrids, Phytoplasma disease, Resistance breeding, Sri Lanka Green Dwarf, Sri Lanka Tall, Weligama Coconut Leaf Wilt Disease

\section{Introduction}

Weligama Coconut Leaf Wilt Disease (WCLWD) was first reported in Sri Lanka in the year 2006 and subsequently the intra-cellular pathogen phytoplasma was identified to be the causal organism of this disease (Perera et al., 2012). Diseases caused by phytoplasma have been reported in coconut in several coconut growing countries. Among them lethal yellowing, found in Africa and the Caribbean is the most devastating, killing the infected palm within a relatively short period of time (Baudouin et al. 2009). Kerala root wilt which is reported in India is another disease caused by phytoplasma. This is a debilitating disease reducing the vigour of the palm resulting in the gradual

\footnotetext{
*Genetics and Plant Breeding Division, Coconut Research Institute, Lunuwila, 61150, Sri Lanka.

Email: chandrikaperera2003@yahoo.com
} 
decline of its productivity (Nair et al.2006). In addition, coconut is plagued with several other diseases, such as Cadang-cadang disease in the Philippines, Wilt disease in Kalimantan Indonesia which are known to be caused by intracellular pathogens for which there are no quick remedial measures.

Yellowing, flaccidity and marginal necrosis of leaflets are the prominent symptoms appearing on the coconut palms infected by WCLWD. Based on the severity of these symptoms on each frond of each diseased palm, an index has been developed to determine the significance of the disease in affected palms (Nainanayake et al. 2010). The index helps in categorizing diseased palms based on the severity of disease aiming at developing appropriate management strategies. Among these symptoms, flaccidity is the most important because the yellowing may occur due to various other factors while the marginal necrosis occurs at a later stage of disease infection. Waidyarathne and Samarasinghe (2014) mathematically proved that flaccidity accounts for $57 \%$ of the disease variability and yellowing followed by necrosis, respectively, explains the remainder as 37 and $6 \%$.

There are no practical treatments to control diseases caused by phytoplasma and hence they are considered to be incurable. Consequently, the disease management strategies are devised either to curtail the spread of the disease or to eradicate it. Breeding coconuts for resistance/tolerance to phytoplasma has been considered the most viable option in the long run in managing such diseases. However, the existence of sources of resistant genes among the coconut germplasm is essential for this exercise to be a practicality.

Sri Lanka tall is the most commonly grown coconut cultivar in Sri Lanka including the Southern Province where WCLWD is present. In addition, the improved dwarf $\mathrm{x}$ tall coconut hybrid (CRIC65) is also famous among the Sri Lankan coconut growers. General observations revealed the coconut cultivar Sri Lanka tall to be susceptible to WCLWD. However, the coconut hybrid CRIC65 seemed to be showing less disease symptoms on general observations.

Southern Province of Sri Lanka, where WCLWD is present is included in the 'mini coconut triangle' which is the second most important coconut cultivation area in the country. Approximately 250,000 palms in the Southern area are estimated to be infected with WCLWD (Everard, 2013). Since there are no practical chemical treatments for phytoplasma diseases, measures have been taken to dispose of all the disease palms by uprooting with a view to curtail the spread of the disease and to eliminate the disease in the long run. In addition, planting new coconut seedlings is prohibited by law until the disease resistant cultivars are introduced (Everard, 2013). Therefore identification of resistance of available cultivars became very important and accordingly, the current research was carried out to investigate the comparable levels of susceptibility or resistance/tolerance of Sri Lanka tall and CRIC65 coconut cultivars to WCLWD.

\section{Materials and Methods}

Eight coconut estates which were planted with Sri Lanka tall (SLT) and CRIC65 hybrids (Lanka Green dwarf x Sri Lanka tall and Sri Lanka Yellow Dwarf $\mathrm{x}$ Sri Lanka tall) as a mixed plantation or in close proximity were observed to determine the presence or absence of WCLWD symptoms and the severity of the disease if present. In addition to the disease status, the management of the estates and the disease incidence in the surrounding estates were also recorded (Table 01). Out of the 08 estates in which the general observations were recorded an extent of about 04 acres of Chalagiri estate was selected for detailed analysis using the disease severity index explained below.

In the selected estate the severity status of the disease in each of 109 palms were assessed using WCLWD index (I) shown in equation 1. The index has been designed by modelling experts' decision on palm severity status using three WCLWD symptoms; flaccidity, yellowing and marginal necrosis (Figure 01). Leaf symptoms were initially visually quantified by observations made from the ground level by a 
group of experts, as the percentage spread on leaflets and then converted to the grade points considering the distribution of each disease symptom to calculate the index. Accordingly, there were five grades (1-5) for flaccidity based on the percentage spread of flaccidity on the coconut frond such that grade $1=0-5 \%, 2=5$ $30 \%, 3=30-45 \%, 4=45-60 \%$ and $5=>60 \%$. There were two grades for yellowing as grade $1=$ $<20 \%, 2=>20 \%$. Percentage spread of marginal necrosis varied between two grades as grade 1 $=<5 \%, 2=>5 \%$.

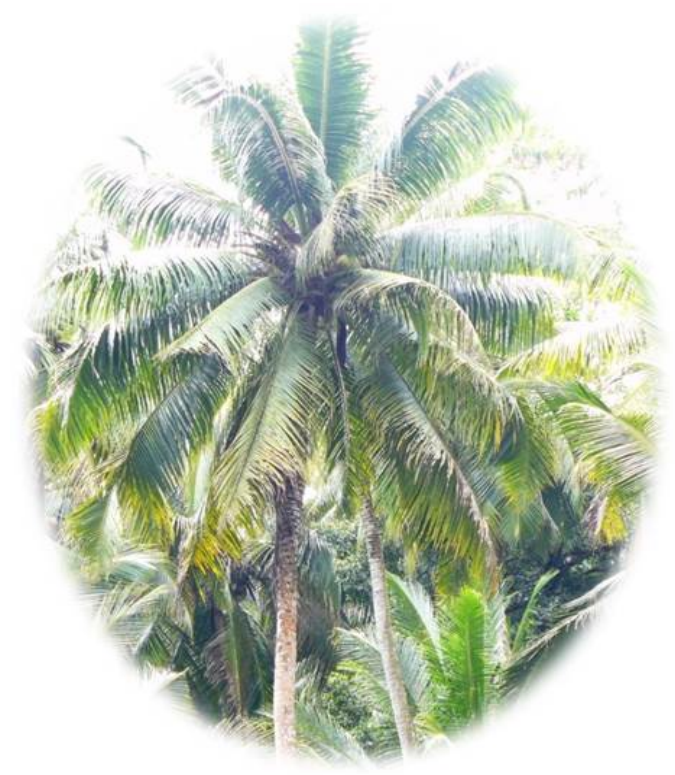

Figure 01. Diseased palm showing the symptoms of flaccidity, yellowing and marginal necrosis

$I=\frac{\sum(a \cdot F+b \cdot Y+c \cdot N)}{L}$

where, $\mathrm{F}, \mathrm{Y}, \mathrm{N}$ are grade points assigned to flaccidity, yellowing, and necrosis respectively, $\mathrm{L}=$ total number of leaves in the spiral and $\mathrm{a}, \mathrm{b}$ $\& \mathrm{c}=$ weights given to $\mathrm{F}, \mathrm{Y}, \mathrm{N}$.

The disease index values vary from $0-$ 100. Palms which are free from the symptoms are assumed apparently healthy palms. If the score of the index is $<50$, such palms are considered mildly infected by WCLWD. Moderately infected palms are defined by the score value between 50-65, and severe palms are by $\mathrm{I}>60$ in the similar method used by Nainanayake et al. (2010).

\section{Results and Discussion}

\section{General observations and the disease severity Index}

The information related to disease incidence, general management and other relevant details of the observed estates were recorded (table 01).

In general, observations indicate low disease incidence with improved management in both the cultivars (table 01.) In the present situation, estates which are regularly fertilized, with a mulch around the base of the palm and with moisture conservation practises were considered to be managed well. On the other hand the estates which are neglected with minimal management were considered poorly managed. The reduction in disease incidence of well managed estates may be due to increased palm vigour due to the resource availability and vice versa with the poorly managed estates. This observation will be useful in designing management practices for WCLWD in the long run.

The observations indicated the presence of WCLWD in both SLT and the hybrid CRIC65. However, a reduction in the number of diseased palms and the expression of symptoms in CRIC65 compared to those of SLT were also observed. In addition it was recorded that a number of severely diseased palms had already been removed following the government regulations for eradication of WCLWD at the estates Attapattu (Weligama), Chalagiri (Weligama) and Malkaduwawa (Mirissa). As per these guidelines the palms identified to be in the moderate or severe categories are removed from the field and properly disposed. The palm removal in the above estates had taken place 1-3 months prior to the current survey and all the palms removed under the programme were confirmed to be SLT.

The disease incidence as percentage palms infected in each cultivar in the analyzed area is summarized in table 02 . The 28 removed palms all of which were in either moderate or severe 
Table 1. Estates surveyed and their status related to WCLWD $(A=C R I C 65 ; B=S L T)$

\begin{tabular}{|c|c|c|c|c|c|c|}
\hline Estate & $\begin{array}{l}\text { Coconut } \\
\text { cultivar }\end{array}$ & $\begin{array}{l}\text { Age } \\
\text { (years) }\end{array}$ & $\begin{array}{l}\text { Extent } \\
\text { (acres) }\end{array}$ & $\begin{array}{l}\text { Management } \\
\text { status }\end{array}$ & $\begin{array}{l}\text { Disease } \\
\text { incidence }\end{array}$ & Comments \\
\hline $\begin{array}{l}\text { 1. Nakanda estate } \\
\text { (Ahangama) }\end{array}$ & A & 28 & 06 & Good & Healthy & $\begin{array}{l}\text { SLT in adjacent } \\
\text { lands healthy }\end{array}$ \\
\hline $\begin{array}{l}\text { 2. Wickramasena } \\
\text { estate } \\
\text { (Weligama) }\end{array}$ & $\mathrm{A}$ and $\mathrm{B}$ & 12 & 10 & Good & Healthy & - \\
\hline $\begin{array}{l}\text { 3. Attapattu estate } \\
\text { (Weligama) }\end{array}$ & $\mathrm{A}$ and $\mathrm{B}$ & $\begin{array}{l}\text { A (30) } \\
\text { B (50) }\end{array}$ & 20 & Average & $\begin{array}{l}\text { Some } \\
\text { infected } \\
\text { palms }\end{array}$ & $\begin{array}{l}\text { Majority of SLT } \\
\text { and about } 20 \% \\
\text { CRIC65 diseased }\end{array}$ \\
\hline $\begin{array}{l}\text { 4. Chalagiri estate } \\
\text { (Weligama) }\end{array}$ & A & $\begin{array}{l}\text { A (30) } \\
\text { B (50) }\end{array}$ & 6.5 & Poor & $\begin{array}{l}\text { Some } \\
\text { infected } \\
\text { palms }\end{array}$ & $\begin{array}{l}\text { Majority of SLT } \\
\text { and about } 30 \% \\
\text { CRIC } 65 \text { diseased }\end{array}$ \\
\hline $\begin{array}{l}\text { 5. Jhonny-Dale } \\
\text { estate } \\
\text { (Thelijjawila) }\end{array}$ & A & 24 & 03 & Good & $\begin{array}{l}03 \text { infected } \\
\text { palms }\end{array}$ & - \\
\hline $\begin{array}{l}\text { 6. Walowita estate } \\
\text { (Akuressa) }\end{array}$ & $A$ and $B$ & 40 & 65 & Poor & Healthy & $\begin{array}{l}\text { SLT in adjacent } \\
\text { lands healthy }\end{array}$ \\
\hline $\begin{array}{l}\text { 7. Malkaduwawa } \\
\text { estate (Mirissa) }\end{array}$ & A & 08 & 01 & Good & Diseased & $\begin{array}{l}\text { Majority of SLT } \\
\text { and about } 5 \% \\
\text { CRIC65 diseased }\end{array}$ \\
\hline $\begin{array}{l}\text { 8. Kahagala estate } \\
\text { (Kamburupitiya) }\end{array}$ & & & & & Healthy & $\begin{array}{l}\text { SLT in adjacent } \\
\text { lands healthy }\end{array}$ \\
\hline
\end{tabular}

Table 2. Percentage distribution of WCLWD infected palms between two cultivars of coconut

\begin{tabular}{|l|c|c|c|}
\hline \multirow{2}{*}{ Variety } & \multirow{2}{*}{$\begin{array}{l}\text { Number of palms removed } \\
\text { (moderate/severe) }\end{array}$} & Healthy & Status of the palm (\%) \\
\cline { 3 - 4 } & & 35.7 & 64.3 \\
\hline SLT & 40 & 43.9 & 56.1 \\
\hline Hybrid & 0 & & \\
\hline
\end{tabular}


stage were also included in the analysis as infected palms.

The results provided evidence for only marginal difference between SLT and CRIC65 in tolerance for WCLWD; with SLT being more prone and CRIC65 being more tolerant. Infected palms were subjected to further analysis based on the severity of symptoms of each diseased palm and the results are given in table 03 and figure 02 . Out of the three disease symptoms marginal necrosis of leaflets was rare among the studied sample and hence only the disease index and the symptoms; flaccidity and yellowing were considered in this analysis.

\section{Severity of symptoms between the two cultivars}

Table 03 shows the comparison of mean disease index value and leaf symptoms between the two coconut cultivars using two sample ttest. Accordingly, hybrid palms display significantly low disease index value and flaccidity than SLT palms. However, in the surveyed estate, the hybrids were grown under the main SLT plantation hence the hybrid plants can be flaccid as a result of growing under shade.

Moreover, a previous study revealed that the most important leaf symptom in WCLWD classification is flaccidity which determines $57 \%$ of the disease variability (Waidyarathne and Samarasinghe, 2014). Taken together, if the palms are diseased and there is no varietal difference on the tolerance, hybrids are expected to show higher flaccidity level. However, the results in the current study show that the level of flaccidity in hybrids is significantly lower than that in SLT coconuts revealing the tolerance of hybrids to WCLWD.

The disease symptom yellowing can also be due to various other factors such as nutrient deficiency, high heat etc in addition to WCLWD. Further, yellowing is grouped in to two categories based on the distribution when calculating the disease index. In both cultivars yellowing was confined to the first category $(<20 \%$ spread on fronds) indicating that the yellowing is not prominent and does not highly vary at this severity stage in coconut fronds (Figure 02).

Figure 02 illustrates how flaccidity and yellowing symptoms are distributed in various levels (whirls) in the canopies of the infected palms. Both the disease symptoms were declining towards the immature leaf whorls in the canopy except for flaccidity in the third leaf in the spiral of the infected hybrid palms. Both the symptoms in SLT scored higher values at all levels in the spiral in comparison to the hybrid CRIC65 further elaborating the comparative susceptibility and the tolerance respectively of SLT and CRIC65 to WCLWD.

As mentioned in the introduction the coconut hybrid CRIC65 is a hybrid between Sri Lanka dwarf and SLT and either Sri Lanka Green or Sri Lanka yellow Dwarf is used as the female parent while SLT is the common male parent. Accordingly, in actual fact CRIC65 comprises of two hybrids CRIC65 (green) and CRIC65 (yellow) depending on the female parent of the individual hybrid palm. However, in the past both the hybrids had been issued as a single hybrid and once in the field they are hard to be distinguished. Therefore, in the current investigation the hybrid coconut could not be differentiated for the female parent.

In a previous study which included SLT, SLGD, SLYD and King Coconut; SLGD was found to be resistant $(98 \%)$ to WCLWD (Perera et al. 2015). In the same study SLYD was recorded as moderately resistant $(67 \%)$ and both King Coconut (38\% healthy) and SLT (32\% healthy) were found to be marginally resistant to WCLWD. Moreover, SLGD has been found to possess tolerance or resistance to phytoplasma disease lethal yellowing in several countries recording the highest level of resistance among all the cultivars tested (Quaicoe et al. 2009; Nair et al. 2000).

In the current study, the hybrid CRIC65 displayed lower percentage of disease incidence and significant reduction in the levels of symptoms, especially the flaccidity which is the most important symptom despite the fact that they were grown under varying degrees of shade. In addition in the current study there were two 
Table 3. Distribution of mean disease symptoms between coconut cultivars

\begin{tabular}{|l|l|l|l|l|}
\hline Variable & Cultivar & Mean & Std. Error & Significance \\
\hline \multirow{3}{*}{ Index } & Tall & 16.32 & 1.91 & \multirow{2}{*}{0.005} \\
\cline { 2 - 5 } & Hybrid & 9.90 & 0.85 & \\
\hline \multirow{5}{*}{ Flaccidity } & Tall & 5.14 & 0.73 & \multirow{2}{*}{0.010} \\
\cline { 2 - 5 } & Hybrid & 2.97 & 0.29 & \\
\hline \multirow{2}{*}{ Yellowing } & Tall & 1.86 & 0.28 & \multirow{2}{*}{0.088} \\
\cline { 2 - 6 } & Hybrid & 1.26 & 0.20 & \\
\hline
\end{tabular}

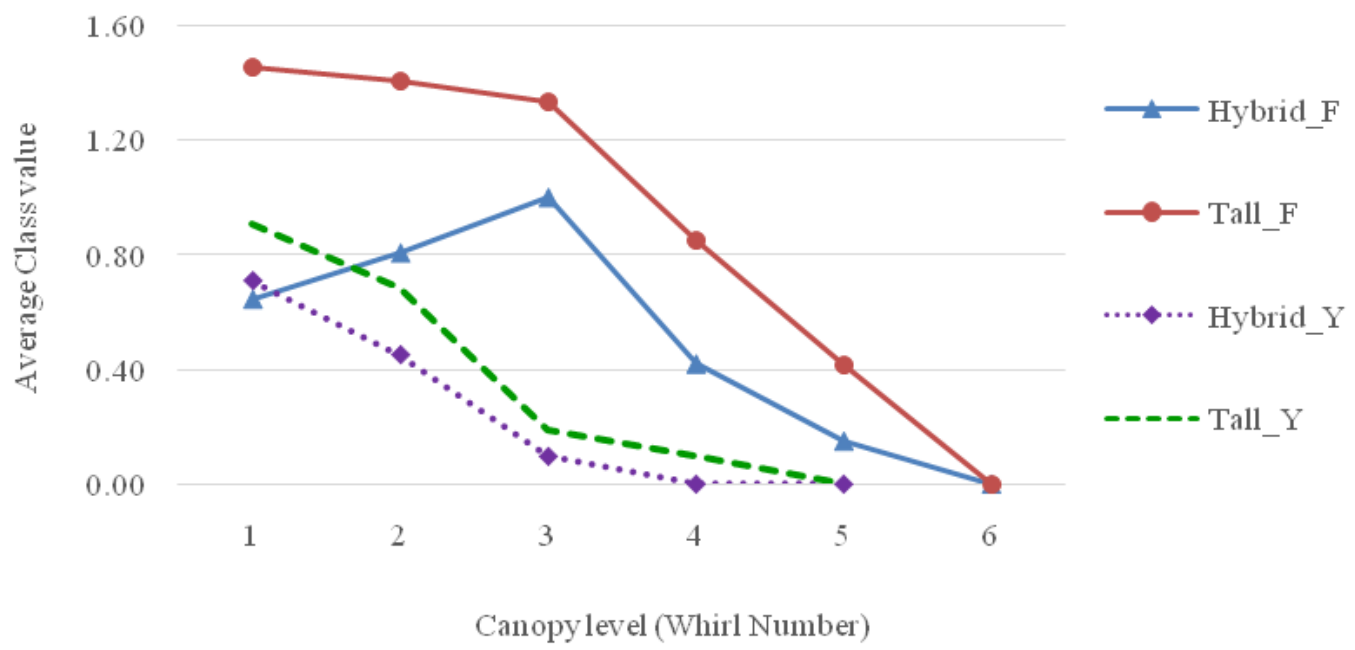

Figure 2. Distribution of WCLWD symptoms among different levels of canopy (F - Flaccidity and Y - Yellowing) in Hybrid and Tall cultivars 
hybrids; one involving SLGD as a parent and the other without and thus the tolerance levels of the two hybrids can vary. Given the above facts it is reasonable to assume that the hybrids involving SLGD as a parent would be more tolerant to WCLWD than the hybrids having SLYD as a parent. In addition it should be noted that $35.7 \%$ of SLT palms, remained healthy in the current study, under the same disease pressure.

\section{Conclusions}

As mentioned above, planting of WCLWD resistant/tolerant cultivars would be one of the most viable options in managing this disease. In this respect the current study provides an insight into the WCLWD resistance of the favoured commercial coconut cultivars in Sri Lanka. Furthermore, the findings of the current study can be combined with the results of the previous studies to select parents for a hybridization programme aiming at WCLWD tolerance. Accordingly, SLGD and SLT which remain healthy under the same disease pressure and selected within the disease prevailing area itself can be recommended as parents for hybridization aiming at resistance/tolerance to WCLWD. Moreover, proper management of the coconuts stands of any cultivar will be of use to increase the palm health any vigour for reduction of WCLWD incidence.

\section{Acknowledgements}

The authors wish to thank Dr. L. Perera, the head of the Genetics and Plant Breeding Division of the Coconut Research Institute of Sri Lanka for his assistance.

\section{References}

Baudouin, L., Philippe, R., Quaicoe, R., Dery, S., Dollet, M. 2009. General overview of genetic research and experimentation on coconut varieties tolerant/resistant to Lethal Yellowing. OCL VOL. $16 \mathrm{~N}^{\circ} 2$ MARS-AVRIL.

Everard, J. M. D. T. 2013. Integrated management of Weligama Coconut Leaf Wilt Disease Program in Sri Lanka: Strategies, Implementation and Challenges. Weligama Coconut Leaf Wilt
Disease; Six Years After (Eds. H. P. M. Gunasena, H. A. J. Gunathilake, L. C. P. Fernando, J. M. D. T. Everard) Coconut Research Institute. Lunuwila, Sri Lanka. 13-17

Nainanayaka, A. D., Weerakkody, W. A. T. L., Wijesekara, H. T. R., Waidyaratne, K. P. and Subhathma, W. G. R. 2010. Impact of Weligama Coconut Leaf Wilt Disease (WCLWD) on Morphological, Physiological and Yield Aspects of Coconut Palms. Proceedings of the third symposium on plantation crop research Stakeholder empowerment through technological advances (Eds. R. S. Dharmakeerthi and A. M. W. K Senevirathna). Rubber Research Institute of Sri Lanka. Dartonfield, Agalawatta, Sri Lanka. 258:275

Nair, R.V., Rajesh, M.G. and Jacob, P. M. 2000. Chowghat Green Dwarf - a suitable variety for the coconut root (wilt) diseased tract. Indian Coconut Journal. 31(3): 55

Nair, R. V., Thomas, R. J., Jacob, P. M. and Nair, S. N. 2006. Breeding for resistance to coconut root (wilt) disease. In Breeding for resistance to diseases and insect pests in Plantation crops (Eds. R. V. Nair, V. Krishnakumar, Regi J. Thomas, K. Muralidharan and Goerge V. Thomas). 6369

Perera, L., Meegahakumbura, M.K., Wijesekara, H.R.T., Fernando, W.B.S. and Dickinson, M.J. 2012. A Phytoplasma is associated with the Weligama Coconut Leaf Disease in Sri Lanka. Journal of Plant Pathology. 94(1):205-209

Perera, S.A.C.N., Herath, H.M.N.B., Wijesekera, H.T.R, Subhathma, W. G. R. and Weerakkody, W. A. T. L. 2015. Evaluation of Coconut Germplasm in Weligama and Matara area of the Southern Province of Sri Lanka for Resistance to Weligama Coconut Leaf Wilt Disease. Cocos 21: $15-20$

Quaicoe, R., Dery, S., Philippe, R., Baudouin, L., Nipah, J., Nkansah, Poku, J., Arthur, 
Cord 2016, 32 (2)

R., Dare, D., Yankey, E., Pilet, F. and Dollet, M. 2009. Resistance screening trials on coconut varieties to Cape Saint Paul Wilt Disease in Ghana. OCL VOL. $16 \mathrm{~N}^{\circ} 2$ MARS-AVRIL.

Waidyarathne, K. P. and Samarasinghe, S. 2014. Artificial Neural Networks to identify naturally existing disease severity status. Neural Computing and Applications. 25(5): 1031-1041 